\title{
Caracterização fisiológica de isolados de Corynespora cassiicola
}

\author{
Adriana Teramoto ${ }^{1}$, Marise C.M. Parisi ${ }^{2} \&$ Marcos G. Cunha ${ }^{1}$ \\ ${ }^{1}$ Setor Fitossanitário, Escola de Agronomia, Universidade Federal de Goiás, Rodovia Goiânia Nova Veneza, Km 0, Cx. \\ Postal 131, 74001-970, Goiânia, GO; ${ }^{2}$ Centro Experimental Central, Instituto Biológico, Rodovia Heitor Penteado, Km 3 , \\ 13001-970, Campinas, SP.
}

Autor para correspondência: Adriana Teramoto, e-mail: adritera@terra.com.br

\section{RESUMO}

Corynespora cassiicola, agente causal da mancha alvo, causa prejuízos econômicos em diversas culturas. Como a disponibilidade de protocolos padronizados para a produção de inóculo facilitam a condução de testes de patogenicidade, os objetivos deste trabalho foram analisar o crescimento micelial em diferentes temperaturas; avaliar o crescimento micelial e a esporulação de isolados obtidos de diferentes hospedeiros em diferentes regimes de luz; avaliar o efeito da duração de umidade contínua para a máxima germinação dos esporos in vitro e a patogenicidade de sete isolados de C. cassiicola em diversos hospedeiros. As temperaturas para o maior crescimento micelial variaram de 23,3 a $29,5^{\circ} \mathrm{C}$; o crescimento de oito isolados foi indiferente aos regimes de luz, enquanto os outros seis foram mais influenciados pelo escuro contínuo; a maioria dos isolados esporulou mais sob luz contínua; cinco a vinte horas de umidade contínua foi a variação de tempo para que $85 \%$ dos esporos germinassem; quanto à patogenicidade, foi observado que o algodoeiro, o meloeiro e o pepineiro foram os hospedeiros mais suscetíveis, e menos suscetíveis, o tomateiro, aceroleira e o cafeeiro. Para produção massal de inóculo de C. cassiicola recomenda-se utilizar a temperatura de $25^{\circ} \mathrm{C}$ sob luz contínua.

Palavras-chave: esporulação, fotoperíodo, germinação de esporos, inoculação cruzada, patogenicidade.

\section{ABSTRACT}

Physiological characterization of Corynespora cassiicola isolates

Corynespora cassiicola is the causal agent of target spot on several crops of economic importance. Since the availability of standardized protocols for inoculum production makes the conduction of patogenicity tests easier, the objectives of this work were to evaluate the mycelial growth under different temperatures, to evaluate the mycelial growth and spore production under different photoperiods for isolates obtained from different hosts, to evaluate the effect of continuous humidity on spore germination, and the pathogenicity of seven isolates of $C$. cassiicola on several hosts. Temperatures between 23,3 and $29,5^{\circ} \mathrm{C}$ allowed the best growth of the isolates. The growth of eight isolates did not respond to the photoperiods used whereas six isolates were sensitive to the dark. The best sporulation for the majority of isolates was under continuous light. Five to twenty hours of continuous humidity were enough for $85 \%$ of the spores to germinate. As for pathogenicity, cotton, melon and cucumber were the most susceptible hosts, while tomato, coffee and Antilles cherry were the least susceptible. For massal production of C. cassiicola inoculum, a temperature of $25^{\circ} \mathrm{C}$ under continual light is recommended.

Key words: cross inoculation, daylength, pathogenicity, sporulation, spore germination, temperature.

\section{INTRODUÇÃO}

O fungo Corynespora cassiicola (Berk. \& M.A. Curtis) C.T. Wei já foi relatado em mais de 300 hospedeiros em regiões tropicais e subtropicais causando sintomas em folhas, flores, frutos, raízes e ramos (Farr et al., 2009). No Brasil, na cultura da soja, o patógeno infecta tanto a parte aérea como o sistema radicular e surtos severos têm sido observados, desde as zonas mais frias do sul às chapadas dos Cerrados (Embrapa, 2011). Em outras culturas como cacaueiro, pepineiro ou aceroleira, infecta as folhas, o que reduz a área fotossintética ativa e, consequentemente, a produção (Duarte et al., 1978; Poltronieri et al., 2003; Verzignassi et al., 2003). No mamoeiro, tomateiro e cafeeiro causa lesões também nos frutos, o que os deprecia ou os inviabiliza para a comercialização (Santos et al., 2001; Reis e Boiteux, 2007; Souza et al., 2009).

Devido à ocorrência de C. cassiicola em diversas culturas de importância econômica elucidar quais são as condições favoráveis para a esporulação deste fungo, com a finalidade de produção massal de inóculo, e das condições favoráveis para o ótimo desenvolvimento do patógeno (interação ambiente-patógeno) tanto para a viabilização de estudos epidemiológicos como para medidas de controle, representa uma contribuição relevante. Algumas pesquisas neste sentido já foram realizadas, porém apenas para isolados de algumas culturas, como a soja (Almeida e Yamashita, 1976); mamoeiro; cacaueiro (Duarte et al., 1983) e aceroleira (Celoto, 2009), não contemplando isolados das culturas como o pepineiro, algodoeiro, cafeeiro, meloeiro e tomateiro. 
A determinação do tempo de molhamento contínuo em que irá ocorrer a máxima germinação dos esporos do patógeno in vitro fornece subsídios para estudos epidemiológicos, que são básicos para a escolha do melhor método de controle no campo. O tempo de molhamento para a máxima germinação de conídios foi determinado por Stone e Jones (1960) com isolados da cultura da soja e do gergelim; Chee (1988) para isolados da seringueira e Celoto (2009) para isolados da aceroleira.

Já experimentos de inoculações cruzadas são fundamentais para a recomendação de uma eficiente rotação de culturas visando redução de fonte de inóculo na área de cultivo, contribuindo para o manejo da doença nos campos de produção (Jones, 1961; Spencer \& Walters, 1969; Kingsland, 1986; Lakshmanan et al., 1990; Silva et al., 1998; Cutrim e Silva, 2003; Poltronieri et al., 2003; Oliveira et al., 2006; Oliveira et al., 2007).

Os objetivos deste trabalho foram analisar o crescimento micelial em diferentes temperaturas; avaliar o crescimento micelial e a esporulação de isolados obtidos de diferentes hospedeiros em diferentes regimes de luz; avaliar o efeito da duração de umidade contínua para a máxima germinação dos esporos in vitro e a patogenicidade de sete isolados de C. cassiicola em diversos hospedeiros.

\section{MATERIAL E MÉTODOS}

\section{Local de execução dos experimentos}

Os experimentos foram realizados no Núcleo de Pesquisa em Fitopatologia da Escola de Agronomia da Universidade Federal de Goiás, localizada em Goiânia, GO.

\section{Obtenção dos isolados}

Nos ensaios foram utilizados 16 isolados de $C$. cassiicola obtidos de diferentes hospedeiros e regiões (Tabela 1). Todos os isolados foram obtidos de folhas com sintomas típicos da mancha alvo, monospóricos, isolados primeiramente em meio ágar-água (AA), seguido da transferência das bordas de colônias para batata-dextroseágar(BDA), sendo posteriormente devidamente preservados em BDA recoberto com óleo mineral. Estes isolados fazem parte da micoteca do Núcleo de Pesquisa em Fitopatologia da Escola de Agronomia e Engenharia de Alimentos, da Universidade Federal de Goiás.

\section{Efeito da temperatura e do regime de luz no crescimento micelial de Corynespora cassiicola}

Discos de micélio de $0,5 \mathrm{~cm}$ de diâmetro de 14 isolados de C. cassiicola foram retirados de colônia com aproximadamente dez dias de idade e transferidos para o centro de placas de Petri, de nove centímetros de diâmetro, contendo batata-dextrose-ágar (BDA). As placas foram mantidas em incubadoras ajustadas para temperaturas de $15,20,25,30$ e $35^{\circ} \mathrm{C}$, sob escuro contínuo, durante aproximadamente dez dias (tempo necessário para a colônia
TABELA 1 - Isolados de Corynespora cassiicola utilizados, seus hospedeiros e procedência

\begin{tabular}{lll}
\hline \hline Isolados & Hospedeiro & \multicolumn{1}{c}{ Procedência } \\
\hline PESP01 & Pepino & Indaiatuba, SP \\
PESP02 & Pepino & Promissão, SP \\
PESP03 & Pepino & Indaiatuba, SP \\
PESP04 & Pepino & Promissão, SP \\
PESP05 & Pepino & Piedade, SP \\
PESP06 & Pepino & Mogi das Cruzes, SP \\
PEGO07 & Pepino & Goiânia, GO \\
SOSP01 & Soja & Piracicaba, SP \\
SOMA01 & Soja & Riachão, MA \\
SOMA02 & Soja & Riachão, MA \\
ALSP01 & Algodão & Paranapanema, SP \\
CAES01 & Café cv. Conilon & Linhares, ES \\
HOPA01 & Hortênsia & Belém, PA \\
ACSP01 & Acerola & Junqueirópolis, SP \\
METO01 & Melão & Guaraí, TO \\
TOGO01 & Tomate & Goianápolis, GO \\
\hline
\end{tabular}

ocupar todo o diâmetro da placa). O mesmo procedimento foi realizado para o experimento de regime de luz, com diferença apenas que as placas foram submetidas a temperatura de $25^{\circ} \mathrm{C}$ em escuro contínuo, luz contínua ou fotoperíodo de 12 horas de luz.

$\mathrm{O}$ crescimento radial do fungo foi medido em dois eixos perpendiculares e, logo após, calculada a média aritmética dos valores, a intervalos de dois dias, até o fungo colonizar totalmente a placa. Foram utilizadas apenas as médias da última avaliação para os cálculos estatísticos.

O delineamento experimental utilizado no ensaio de temperaturas foi o inteiramente casualizado em esquema fatorial $14 \times 5 \times 3$ (14 isolados do patógeno, cinco temperaturas de incubação e três repetições). No caso do experimento de regimes de luz, o delineamento foi inteiramente casualizado em esquema fatorial $14 \times 3 \times 3$ (14 isolados de patógeno, três regimes de luz e três repetições).

As análises estatísticas foram realizadas no programa SISVAR 5.1 (Ferreira, 2008). A variável dependente (crescimento micelial) significativa no teste $\mathrm{F}$ da análise de variância foi submetida à análise de regressão. $\mathrm{O}$ ajuste do modelo de regressão foi realizado utilizando-se as repetições das variáveis estudadas. Avaliou-se o ajuste dos modelos linear, quadrático e cúbico. $\mathrm{O}$ modelo escolhido para plotar o gráfico foi aquele com maior coeficiente de determinação $\left(\mathrm{R}^{2}\right)$ e menor quadrado médio dos desvios (Sokal e Rohlf, 1995). Para determinar a temperatura ótima de crescimento micelial foi realizada a derivada da equação de regressão com melhor ajuste. Foi estudada também a interação entre os isolados e as temperaturas, e, quando significativas, as médias foram discriminadas pelo teste de Tukey a 5\% de probabilidade.

Para o experimento de regime de luz, os dados foram submetidos à análise de variância e verificada a interação entre os isolados e os regimes de luz e, quando significativa, as médias foram discriminadas pelo teste Tukey a $5 \%$ de probabilidade. 


\section{Efeito do regime de luz na esporulação de Corynespora cassiicola}

A montagem deste experimento foi exatamente igual ao realizado para o experimento de efeito do regime de luz no crescimento micelial. Para quantificação da esporulação adicionou-se $40 \mathrm{~mL}$ de água destilada em cada placa de Petri, seguido da liberação dos esporos com um pincel. Um mililitro da suspensão obtida foi colocada com uma pipeta em câmara de Neubauer, para a quantificação da concentração de esporos da suspensão. Realizou-se a contagem em cada placa três vezes.

$\mathrm{O}$ delineamento experimental utilizado foi $\mathrm{o}$ inteiramente casualizado em esquema fatorial $14 \times 3 \times 3(14$ isolados, três regimes de luz e três repetições).

Os dados obtidos foram submetidos à análise de variância e, quando significativos, as médias foram discriminadas pelo teste de Tukey a $5 \%$ de probabilidade.

\section{Efeito do período de molhamento contínuo na germinação in vitro de esporos de Corynespora cassiicola \\ Colônias de dez isolados de C. cassiicola, com} dez dias de idade, foram utilizadas para preparo de suspensões devidamente calibradas a $10^{4}$ esporos $\mathrm{mL}^{-1}$. Logo após, quatro gotas de $50 \mu \mathrm{L}$ de suspensão de esporos de cada isolado foram colocadas no centro de cada placa de Petri. A placa foi tampada e colocada dentro de uma caixa gerbox, que continha papel de filtro umedecido no fundo para manter elevada a umidade relativa do ar. As caixas foram mantidas em BOD a temperatura de $25^{\circ} \mathrm{C}$ por $1,2,4,8,10,12$ e 24 horas de umidade contínua. Cada tratamento constou de quatro repetições (uma placa por gerbox). Decorrido o tempo de cada tratamento, foi acrescido $20 \mu \mathrm{L}$ de lactoglicerol a cada gota da suspensão fúngica para paralisar as atividades biológicas dos esporos. Foram contados 100 esporos de cada repetição. Considerou-se germinado o conídio que apresentava tubo germinativo de tamanho igual ou maior que o comprimento do esporo. O delineamento experimental foi inteiramente casualizado e esquema fatorial dez (isolados do patógeno) por sete (intervalos de molhamento contínuo), com quatro repetições.

As variáveis significativas no teste $\mathrm{F}$ da análise de variância foram submetidas à análise de regressão. $\mathrm{O}$ ajuste do modelo de regressão foi realizado utilizando-se as repetições das variáveis estudadas transformadas em arc sen $(\mathrm{x} / 100)^{1 / 2}$. O modelo escolhido para plotar o gráfico foi aquele com maior coeficiente de determinação $\left(\mathrm{R}^{2}\right)$ e menor quadrado médio dos desvios (Sokal \& Rohlf, 1995). Para tanto foi utilizado o Programa SigmaPlot 6.0 (Systat Software Inc.). A quantidade de horas de molhamento contínuo necessária para a germinação de $85 \%$ dos esporos de cada isolado foi estimada através dos gráficos. Foi estudada também a interação entre os isolados e os períodos de umidade contínua, e, quando significativas, as médias foram discriminadas pelo teste de Tukey a 5\% de probabilidade.
Patogenicidade de diversos isolados de $C$. cassiicola

A patogenicidade dos isolados PESP04, ALSP01, CAES01, ACSP01, TOGO01 METO01 e SOMA02 de $C$. cassiicola foi verificada por meio de testes de inoculações cruzadas com mudas de pepino (híbrido Nikkey), algodão (var. Delta Opal), café (cv. Catuaí Vermelho), acerola (propagada por semente, sem variedade definida), tomate (híbrido Tyler), melão (Redondo Gaúcho) e soja (cv. BRS Valiosa), sendo que cada tratamento (cultura) constou de três vasos com duas plantas cada, no caso do pepino, algodão, tomate, melão e soja. As mudas de café e acerola foram adquiridas em saquinhos plásticos contendo uma muda por saquinho, sendo utilizadas três repetições (três mudas) para cada tratamento. O delineamento experimental utilizado foi inteiramente casualizado, sendo um fatorial 7 (isolados de C. cassiicola) x 7 (espécies hospedeiras), com três repetições. Quando as mudas atingiram dois pares de folhas verdadeiras foram inoculadas, com utilização de pulverizador manual (capacidade de $500 \mathrm{~mL}$ ), com suspensão de esporos de isolados de $C$. cassiicola obtidos da mesma espécie hospedeira e das outras espécies de plantas, na concentração de $10^{4}$ conídios $\mathrm{mL}^{-1}$, até o ponto de escorrimento superficial. Após a inoculação, os vasos foram mantidos por 24 horas em câmara úmida. A seguir os vasos foram mantidos por aproximadamente uma ou mais semanas em casa de vegetação até o aparecimento dos primeiros sintomas foliares da mancha alvo. Assim, mudas de pepino foram inoculadas com isolados de C. cassiicola obtidos de plantas de pepino, algodão, café, acerola, tomate, melão e soja. $\mathrm{O}$ mesmo teste foi realizado com as demais espécies.

A avaliação foi feita diariamente até o aparecimento dos sintomas típicos da doença, e posterior confirmação da identificação do patógeno por meio de reisolamento do mesmo em meio de cultura BDA.

\section{RESULTADOS E DISCUSSÃO}

\section{Efeito da temperatura e do regime de luz no crescimento micelial de Corynespora cassiicola}

Houve interação significativa entre os isolados e as temperaturas para o crescimento micelial $(\mathrm{F}=61,43 ; \mathrm{P}<0,01)$. A faixa ideal de temperatura ótima para o crescimento micelial do fungo foi de 20 a $30^{\circ} \mathrm{C}$, com ótimo variando de 23,3 a $29,5^{\circ} \mathrm{C}$, obtidos pela derivada das equações de regressão (Figura 1). Quatro isolados cresceram mais a temperaturas próximas a $29^{\circ} \mathrm{C}(\mathrm{PESP} 04, \mathrm{PESP} 05$, SOMA02 e ALSO01); seis isolados com temperaturas entre 27 e $28^{\circ} \mathrm{C}$ (SOSP01, SOMA01, PESP06, ACSP01, METO01 e TOGO01); dois isolados entre 25 a $26^{\circ} \mathrm{C}$ (PESP02, e HOPA01) e, dois isolados a temperatura menor que $25^{\circ} \mathrm{C}$ (PESP01 e CAES01).

As temperaturas de 15 e $35^{\circ} \mathrm{C}$ foram as mais limitantes para o crescimento dos diferentes isolados de C. cassiicola. Dos quatorze isolados utilizados, seis apresentaram os menores crescimento a $15^{\circ} \mathrm{C}$ (PESP01, PESP05, SOMA01, 
A. Teramoto et al.

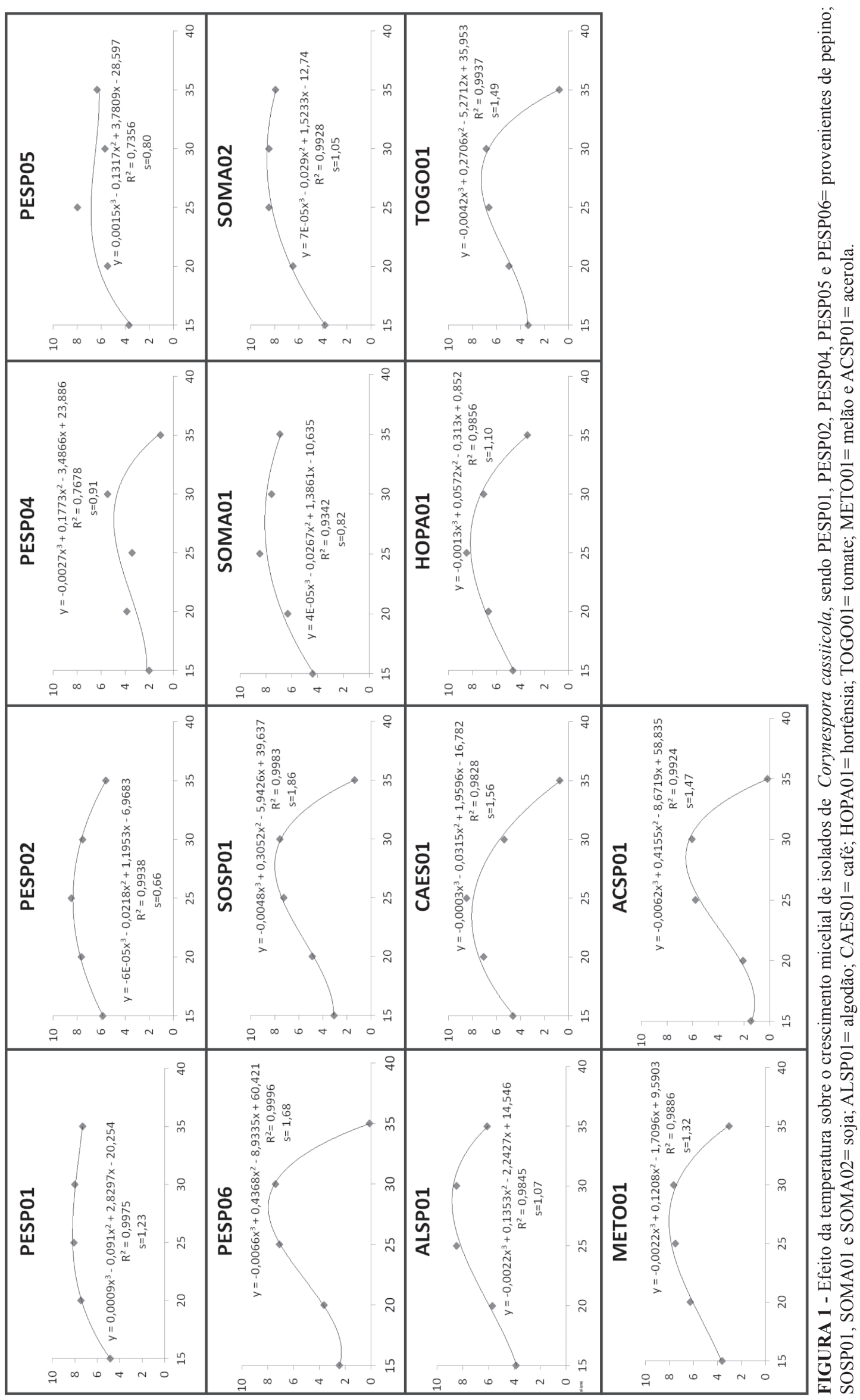


SOMA02, ALSP01 e METO01) e sete (PESP04, PESP06, SOSP01, CAES01, HOPA01, TOGO01 e ACSP01) a $35^{\circ} \mathrm{C} . \mathrm{O}$ crescimento do isolado PESP02 foi semelhante a 15 e $35^{\circ} \mathrm{C}$.

$\mathrm{O}$ resultado obtido com o isolado de acerola foi de $28^{\circ} \mathrm{C}$, superior ao obtido por Celoto (2009), que foi de $26,1^{\circ} \mathrm{C}$. Um fato interessante é que os isolados de acerola utilizados nesse e no presente estudo, foram todos provenientes da mesma cidade (Junqueirópolis, SP).

Para o isolado de tomate, a temperatura ótima foi de $28^{\circ} \mathrm{C}$, um pouco superior ao utilizado por Cutrim \& Silva (2003), $25^{\circ} \mathrm{C}$. Nesse caso, os autores utilizaram essa temperatura para produção de inóculo, porém não foi o objetivo principal do ensaio. Dentre os isolados de pepino, as temperaturas que mais favoreceram o crescimento micelial variaram de 24,4 a $29,3^{\circ} \mathrm{C}$. Os isolados PESP02 e PESP04, provenientes do mesmo município, tiveram comportamentos diferentes: o PESP02 cresceu mais nas temperaturas de $24,7^{\circ} \mathrm{C}$ e o $\mathrm{PESP} 04$, a $28,6^{\circ} \mathrm{C}$.

Os isolados de soja SOMA01 e SOMA02, procedentes da mesma localidade, também tiveram comportamentos distintos, com melhor desenvolvimento micelial a $27,9^{\circ} \mathrm{C}$ e $29,5^{\circ} \mathrm{C}$, respectivamente. Resultados diferentes aos obtidos por Hartman et al. (1999), em que a temperatura ótima para o crescimento de isolados de $C$. cassiicola de soja foi de 18 a $21^{\circ} \mathrm{C}$, porém para alguns isolados também foi de $28^{\circ} \mathrm{C}$. Essa diferença ocorreu provavelmente pela adaptação dos isolados do patógeno com nichos ecológicos distintos, como por exemplo, a temperatura. Os isolados brasileiros foram coletados na região Nordeste, com temperaturas médias anuais variando de 24 a $26^{\circ} \mathrm{C}$, enquanto que o americano, na região CentroOeste dos Estados Unidos, onde se localiza o Cinturão do Milho e da Soja, com médias anuais de $21^{\circ} \mathrm{C}$.

Já para o isolado de hortênsia, o resultado coincidiu com o obtido por Sobers (1966) em que o máximo crescimento ocorreu entre 22 e $26^{\circ} \mathrm{C}$. Porém, para o isolado de café a temperatura ideal foi de $23,3^{\circ} \mathrm{C}$, inferior ao utilizada por Souza et al. (2009) de $26^{\circ} \mathrm{C}$, mas também não foi o foco dos autores a determinação da temperatura de melhor crescimento micelial, e sim apenas a produção massal de inóculo.

Com base nos resultados obtidos e os observados por outros ensaios, percebe-se claramente que há variações entre os isolados e até mesmo dentre os isolados provenientes do mesmo hospedeiro, porém todos se encaixam na faixa de temperatura entre 20 a $30^{\circ} \mathrm{C}$. Assim, é sensato utilizar temperatura próxima a $25^{\circ} \mathrm{C}$ quando se quer multiplicar o inóculo deste patógeno.

Com relação à influência do regime de luz no crescimento micelial, observa-se que os isolados PESP02, PESP04, PESP05, SOMA01, SOMA02, HOPA01, METO01 e ACSP01 foram indiferentes ao regime de luz utilizado. Para os isolados PESP01, PESP06 e SOSP01, o fotoperíodo de luz alternada foi o regime de luz mais prejudicial ao crescimento. Os isolados ALSP01 e CAES01 apresentaram menor crescimento sob luz contínua, a semelhança do
TOGO01, que teve seu crescimento reduzido também pelo regime de luz alternada.

No caso dos isolados de pepino PESP02 e PESP04, provenientes da mesma localidade, nota-se comportamento semelhante, ou seja, apresentaram crescimentos indiferentes aos regimes de luz utilizados.

Almeida \& Yamashita (1976) observaram que o crescimento de $C$. cassiicola obtido de soja foi favorecido pela luz continua e prejudicado pelo escuro contínuo, o que é totalmente contraditório ao resultado obtido com os três isolados de soja deste trabalho (SOSP01, SOMA01 e SOMA02), que foram indiferentes aos regimes de luz testados.

Para o isolado de tomate o escuro contínuo resultou em maior crescimento micelial, seguido de fotoperíodo e luz contínua. Esse resultado contraria o obtido por Cutrim \& Silva (2003), que utilizaram iluminação contínua para o crescimento dos isolados de tomate.

\section{Efeito do regime de luz na esporulação de Corynespora cassiicola}

O efeito do regime de luz na produção de esporos, para a maioria dos isolados foi efetivo (Tabela 2). Para os isolados PESP02 e ACSP01, o período de luz alternada favoreceu a esporulação, enquanto para PESP04, PESP05, PESP06, SOMA01, SOMA02, ALSP01 e HOPA01, a luz contínua foi mais favorável, concordando, com a recomendação de produção de inóculo por Abul-Hayja \& Williams (1996). Os isolados TOGO01 e METO01 esporularam mais sob escuro contínuo e os isolados PESP01, SOSP01 e CAES01 foram indiferentes.

Os resultados obtidos com os isolados de soja são parcialmente concordantes aos obtidos por Almeida \& Yamashita (1976), que observaram maior produção de esporos sob luz contínua. No presente trabalho, dos três isolados de soja utilizados, um, procedente de Piracicaba, SP, foi indiferente aos regimes de luz testados, os outros dois, procedentes de Riachão, MA, apresentaram comportamentos diferentes: um esporulou mais sob luz contínua e outro esporulou melhor tanto sob luz contínua como sob escuro. Provavelmente a procedência dos isolados possa ser a responsável por essas diferenças de comportamento.

Duarte et al. (1983) estudaram dois isolados de C. cassiicola do mamoeiro e cacaueiro e concluíram que o isolado de mamoeiro esporulou mais sob escuro e do cacaueiro sob luz contínua. Os autores analisaram outras características morfológicas e fisiológicas desses isolados e os resultados sugerem que o patógeno possa ter raças diferentes. Esse fato explicaria as diferenças encontradas no crescimento micelial, regimes de luz e esporulação entre e dentre os isolados do patógeno.

A partir dos resultados obtidos neste ensaio, pode-se sugerir para produção massal de inóculo de C. cassiicola, que seja utilizada temperatura próxima a $25^{\circ} \mathrm{C}$ e em regime de luz contínua ou escuro contínuo, dependendo do isolado utilizado, por um período de dez dias após a repicagem. 
A. Teramoto et al.

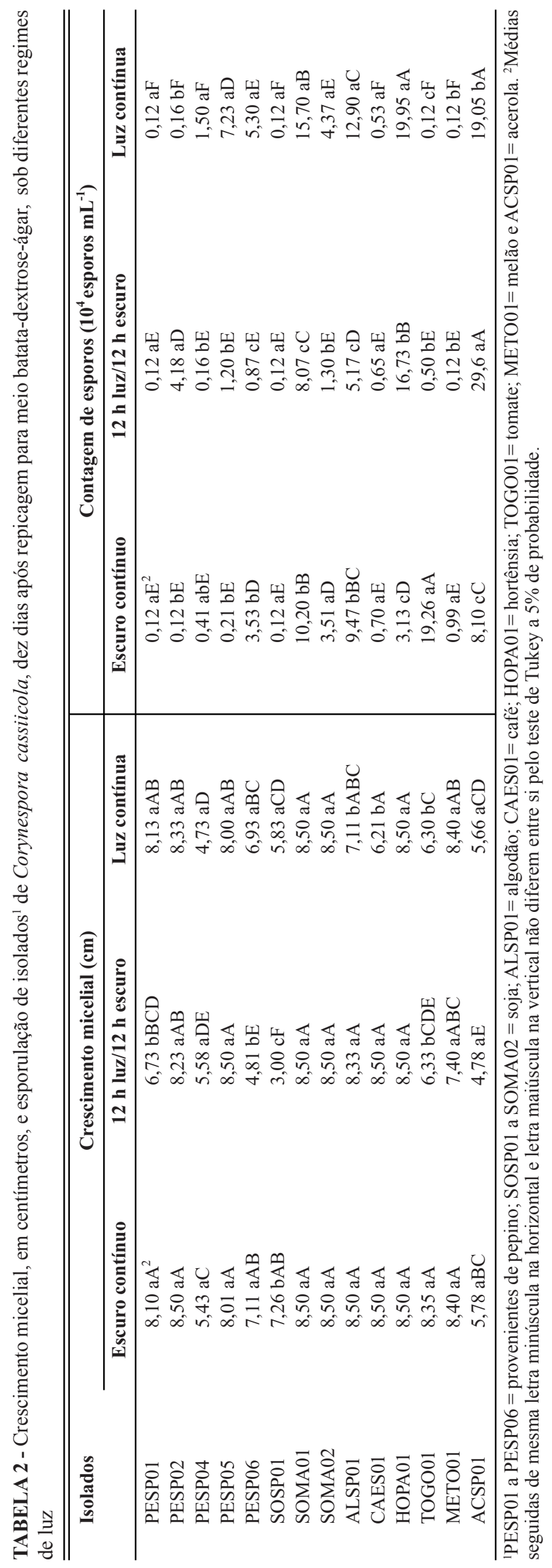


Efeito do período de molhamento contínuo na germinação de esporos de $C$. cassiicola in vitro

No caso de C. cassiicola provenientes de várias espécies hospedeiras, o período de molhamento contínuo para que os conídios alcançassem $85 \%$ de germinação variou de 5,0 a 20 horas (Figura 2). Esse índice foi estabelecido porque a partir desse valor a maioria dos isolados não apresentaram mais diferenças nas médias de germinação. $\mathrm{O}$ isolado de tomate (TOGO01) exigiu o menor período, 5,0 horas, e o isolado de acerola (ACSP01) o maior período, 20 horas. O isolado de algodão (ALSP01) e de melão (METO01) exigiu 5,6 horas; os de pepino 7,6 (PESP04), 9,0 (PESP05) e 8,0 horas (PESP06); algodão (ALSP01) e hortênsia (HOPA01) 9,0 horas; e o de café (CAES01) 10,8 horas.

Celoto (2009) estudou o efeito in vitro da temperatura na germinação de esporos de $C$. cassiicola de acerola e estipulou o período de 10 horas para paralisar a germinação dos esporos e realizar a contagem. A autora não justifica a escolha deste período, porém obteve mais de $80 \%$ de germinação de esporos, o que não ocorreu neste experimento $(68,7 \%)$.

$\mathrm{O}$ período de molhamento necessário para que todos os isolados de pepino atingissem $85 \%$ de germinação in vitro variou de 7,6 a 9,0 horas, independentemente da localidade de origem dos isolados.

O resultado obtido com o isolado de tomate $(5,0 \mathrm{~h})$, algodão $(5,6 \mathrm{~h})$ e melão $(5,6 \mathrm{~h})$ foi um pouco superior ao encontrado por Chee (1988) trabalhando com um isolado de seringueira, para o qual quatro horas de molhamento foram suficientes para a máxima germinação dos conídios.

Portanto, a partir dos resultados obtidos neste ensaio e sabendo-se que a umidade é indispensável para a germinação da maioria dos esporos fúngicos e para a penetração do tubo germinativo no hospedeiro, além de aumentar a suscetibilidade a certos patógenos, afetando a incidência e severidade da doença (Agrios, 2005), pode se iniciar o controle químico preventivo desta a partir de períodos de cinco horas de molhamento contínuo, associados a temperatura próxima aos $25^{\circ} \mathrm{C}$, para os hospedeiros tomate e soja, culturas em que há fungicidas registrados no Ministério da Agricultura (AGROFIT, 2013).

\section{Patogenicidade de isolados de Corynespora cassiicola}

Houve diferenças de suscetibilidade entre as plantas hospedeiras em função da origem dos isolados de C. cassiicola (Tabela 3). As plantas de pepino foram suscetíveis a quase todos os isolados, com exceção ao isolado obtido de acerola (ACSP01). Plantas de algodão e melão foram suscetíveis a todos os isolados. Plantas de café foram suscetíveis aos isolados de acerola (ACSP01) e soja (SOMA01). Plantas de acerola foram suscetíveis aos isolados de pepino (PESP04) e acerola (ACSP01). Plantas de soja não foram suscetíveis aos isolados de acerola (ACSP01) e melão (METO01) e plantas de tomate foram suscetíveis apenas ao isolado de tomate (TOGO01).
Um fato interessante é que plantas de café não foram suscetíveis ao isolado de café, o que foi claramente explicado por Souza et al. (2009), em que o patógeno C. cassiicola apenas é patogênico a Coffea canephora cv. conilon, e as plantas utilizadas foram da cv. Catuaí Vermelho, ou seja, Coffea arabica, que não é hospedeira desse patógeno.

Jones (1961) e Spencer \& Walters (1969) observaram em testes de inoculações cruzadas de isolados de $C$. cassiicola de soja e algodão em hospedeiros soja e algodão, sendo ambos isolados patogênicos. Kingsland (1986) obteve patogenicidade em inoculações cruzadas de isolados obtidos de tomate e pepino, em hospedeiros tomate e pepino. Já Cutrim \& Silva (2003) testaram isolados de tomate em plantas de aceroleira, soja e tomateiro e os resultados foram similares, excetuando-se o resultado em plantas de soja, no qual um isolado não foi patogênico corroborando com o resultado desse trabalho.

$\mathrm{O}$ isolado obtido de pepino (PESP04) foi patogênico à maioria dos hospedeiros testados, com exceção apenas do hospedeiro café e tomate, e também a grande maioria dos isolados foram patogênicos ao hospedeiro pepino, excetuando-se o isolado de acerola (ACSP01). De forma totalmente contraditória ao afirmado por Abul-Hayja \& Williams (1996) em que isolados obtidos de pepino não eram patogênicos a outras culturas, assim como os isolados de outras culturas não eram patogênicos ao pepino. Em concordância com esta afirmação, todos os isolados japoneses inoculados apenas foram patogênicos ao pepineiro, porém, isolados proveniente da Holanda e dos Estados Unidos foram patogênicos ao tomate também (Shimomoto et al., 2011).

Oliveira et al. (2006) inocularam isolados obtidos de tomateiro, soja, pepino e abóbora em diferentes híbridos de pepino e concluíram que todos os isolados originados de pepino e abóbora foram patogênicos, e os de soja e tomate, dependendo do híbrido testado apresentou ou não patogenicidade. Em outro trabalho, Oliveira et al. (2007) inocularam 15 isolados de C. cassiicola originados de diferentes espécies hospedeiras em 12 diferentes espécies vegetais. Os autores constataram que os isolados de pepineiro foram os mais patogênicos e os menos os de trapoeraba e alface, e o hospedeiro mais suscetível foi o mamoeiro e os menos a trapoeraba e o assa-peixe.

$\mathrm{O}$ isolado proveniente de tomateiro (TOGO01) foi patogênico ao pepineiro, algodoeiro, meloeiro, soja e tomateiro. Em concordância com este resultado, isolados obtidos de tomateiro foi patogênico a dois híbridos de pepino (Oliveira et al., 2006) e, segundo Cutrim \& Silva (2003) outro isolado de tomateiro obtido do estado do Maranhão infectou várias plantas cultivadas, como abóbora, maxixe, pimentão, quiabeiro, soja e vinagreira.

Com relação ao hospedeiro mais suscetível, o pepineiro foi um dos mais suscetíveis neste experimento, assim como o meloeiro e o algodoeiro. Dixon et al. (2009) concluíram que o pepineiro foi o hospedeiro mais suscetível reproduzindo o sintoma de mancha alvo 
A. Teramoto et al.

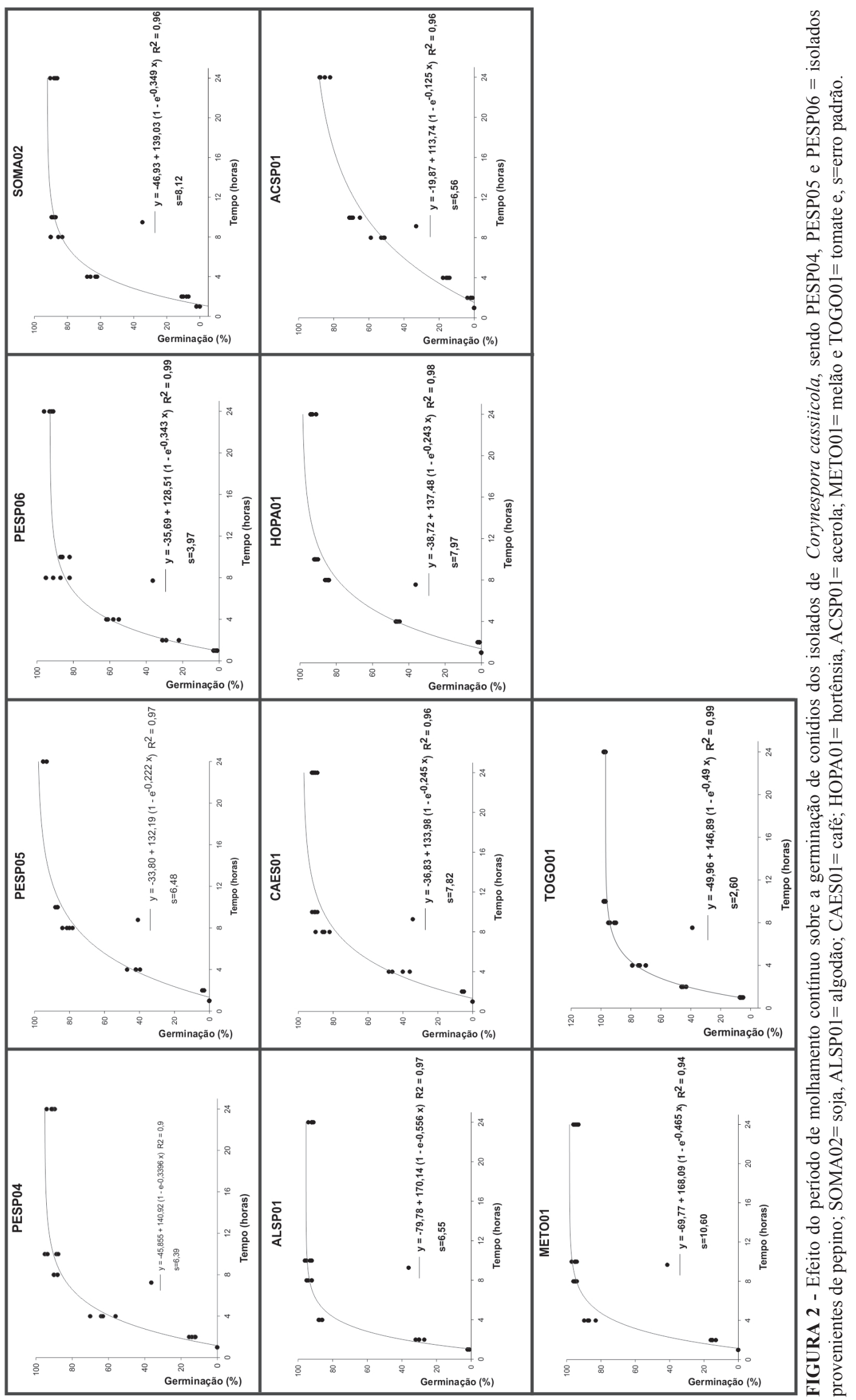


TABELA 3 - Teste de inoculações cruzadas em plantas de pepino, algodão, café, acerola, tomate, melão e soja com isolados de Corynespora cassiicola

\begin{tabular}{|c|c|c|c|c|c|c|c|}
\hline \multirow[t]{2}{*}{ Hospedeiros } & \multicolumn{7}{|c|}{ Isolados } \\
\hline & PESP04 $^{1}$ & ALSP01 & CAES01 & ACSP01 & TOGO01 & METO01 & SOMA02 \\
\hline Pepino & $+^{2}$ & + & + & - & + & + & + \\
\hline Algodão & + & + & + & + & + & + & + \\
\hline Café cv. Catuaí & - & - & - & + & - & - & + \\
\hline Acerola & + & - & - & + & - & - & - \\
\hline Tomate & - & - & - & - & + & - & - \\
\hline Melão & + & + & + & + & + & + & + \\
\hline Soja & + & + & + & - & + & - & + \\
\hline
\end{tabular}

${ }^{1}$ PESP04 = proveniente de pepino; ALSP01 = algodão; CAES01 = café; ACSP01 = acerola; TOGO01 = tomate; METO01 = melão e SOMA02 = soja. ${ }^{2}(+)$ Presença e (-) ausência de sintomas.

em todas as espécies inoculadas (manjericão, feijoeiro, caupi, pepineiro, mamoeiro papaya, soja, batateira-doce e tomateiro). Furukawa et al. (2008) encontraram outro hospedeiro bastante suscetível, a sálvia, no Japão, foi infectada por isolados de C. cassiicola do pepineiro, pimenteira verde, hortênsia, berinjela, tomateiro e soja. Mas um fato interessante foi que o isolado de sálvia não foi patogênico ao pepineiro, pimenteira verde, hortênsia, berinjela, tomateiro e soja.

Com base nos resultados obtidos, conclui-se que o cultivo de pepino próximo ao cultivo de outras hortaliças como tomateiro e meloeiro, e culturas como soja e algodão não é recomendado, principalmente em áreas de ocorrência de $C$. cassiicola, idem para rotação de culturas com essas culturas, uma vez que o patógeno é capaz de sobreviver na matéria orgânica resultante dessas plantas por um período de até dois anos (Kurosawa et al., 2005).

Como conclusão geral deste trabalho tem-se que cada isolado, mesmo provindo do mesmo hospedeiro e da mesma localidade, comportou-se de maneira diferente quando submetido às diferentes temperaturas, regimes de luz e molhamento contínuo. Quanto à temperatura e o regime de luz ideal para produção massal de inóculo de C. cassiicola variou de 23,3 a $29,5^{\circ} \mathrm{C}$, sob escuro ou luz contínua. $\mathrm{O}$ tempo para ocorrer a máxima germinação dos conídios foi bastante variável, de 5 e 20 horas de molhamento contínuo. Com relação à patogenicidade, foram evidenciados hospedeiros mais suscetíveis, como o pepineiro, algodoeiro e meloeiro, e menos suscetíveis, como o tomateiro, aceroleira e o cafeeiro.

\section{REFERÊNCIAS BIBLIOGRÁFICAS}

Abul-Hayja Z, Williams PH (1996) Disease handbook - Target leafspot (Corynespora cassiicola). Disponível em: cuke.hort. ncsu.edu/cucurbit/cuke/dshndbk/tls.html. Acesso em 10 de junho, 2007.

Agrios GN (2005) Plant Pathology. $5^{\text {th }}$ Ed. Amsterdan Holanda. Elsevier Academic Press.

AGROFIT (2013) Ministério da Agricultura. Disponível em: extranet.agricultura.gov.br/agrofit_cons/principal_agrofit_cons. Acesso em 14 de janeiro, 2013.

Almeida AMR, Yamashita J (1976) Crescimento e esporulação de Corynespora cassiicola (Berk. \& Curt.) Wei em diferentes meios de cultura. Fitopatologia Brasileira 1:203-206.

Celoto MIC (2009) Fisiologia e manejo de Corynespora cassiicola (Berk. \& M.A. Curtis) C.T. Wei, causador da mancha alvo na cultura da acerola (Malpighia emarginata D.C.) Tese de Doutorado, Universidade Estadual Paulista. Ilha Solteira SP.

Chee KH (1988) Studies on sporulation, pathogenicity and epidemiology of Corynespora cassiicola on Hevea rubber. Journal of Natural Rubber Research 3:21-29.

Cutrim FA, Silva GS (2003) Patogenicidade de Corynespora cassiicola a diferentes espécies de plantas. Fitopatologia Brasileira 28:193-194.

Dixon LJ, Schlub RL, Pernezny K, Datnoff LE (2009) Host specialization and phylogenetic diversity of Corynespora cassiicola. Phytopathology 99:1015-1027.

Duarte MLR, Albuquerque FC, Prabhu AS (1978) Uma nova enfermidade foliar do cacaueiro (Theobroma cacau L.) causada pelo fungo Corynespora cassiicola (Berk. \& Curt.) Wei. Fitopatologia Brasileira 3:259-265.

Duarte MLR, Asano S, Albuquerque FC (1983) Estudo comparativo das características morfológicas e fisiológicas de dois isolamentos de Corynespora cassiicola. Fitopatologia Brasileira 8:205-214.

Embrapa (2011) Tecnologias de produção de soja - região central do Brasil 2012 e 2013. Embrapa Soja Sistemas de Produção n. 15 .

Farr DF, Rossman AY, Palm ME, Maccray EB (2009) Fungal databases. Systematic Botany \& Mycology Laboratory, USDAARS. Disponível em: nt.ars-grin.gov/fungaldatabases. Acesso em 8 de fevereiro, 2010.

Ferreira DF (2008) SISVAR: um programa para análises e ensino de estatística. Revista Symposium 6:36-41.

Furukawa T, Ushiyama K, Kishi K (2008) Corynespora leaf spot of scarlet sage caused by Corynespora cassiicola. Journal of General Plant Pathology 74:117-119.

Hartman GL, Sinclair JB, Rupe JC (1999) Compendium of soybean diseases. St. Paul MN, USA. APS Press.

Jones JP (1961) A leaf spot of cotton caused by Corynespora cassiicola. Phytopathology 51:305-308. 
Kingsland GC (1986) Pathogenicity and epidemiology of Corynespora cassiicola in the Republic of Seychelles. Tropical Pest Managment 32:283-287.

Kurosawa C, Pavan MA, Rezende JAM (2005) Doenças das Cucurbitáceas. In: Kimati H, Amorim L, Rezende JAM, Bergamin Filho A, Camargo LEA (Eds.). Manual de Fitopatologia. Vol 2. Doenças das Plantas Cultivadas. ${ }^{\text {a }}$. Ed. São Paulo SP. Agronômica Ceres. pp. 293-302.

Lakshmanan P, Jeyarajan R, Vidhyasekaran P (1990) A boll rot of cotton caused by Corynespora cassiicola in Tamil Nadu, India. Phytoparasitica 18:171-174.

Oliveira RR, Vida JB, Tessmann DJ, Aguiar BM, Caixeta MP (2006) Reação de híbridos de pepino para cultivo protegido a isolados de Corynespora cassiicola. Fitopatologia Brasileira 31:509-512.

Oliveira RR, Vida JB, Tessmann DJ, Aguiar BM, Caixeta MP, Barboza AL (2007) Patogenicidade de isolados de Corynespora cassiicola a diferentes espécies de plantas. Summa Phytopatologica 33:297-299.

Poltronieri LS, Duarte MLR, Alfenas AC, Trindade DR, Albuquerque FC (2003) Three new pathogens infecting antilles cherry in the state of Pará. Fitopatologia Brasileira 28:424-426.

Reis A, Boiteux LS (2007) Mancha-de-corinéspora do tomateiro. Embrapa Hortaliças Comunicado Técnico 41.

Santos AA, Freire FCO, Cardoso JE (2001) Ocorrência da podridão interna do mamão no Estado do Ceará. Fitopatologia
Brasileira 26:673.

Silva WPK, Deverall BJ, Lyon BR (1998) Molecular, physiological and pathogenic characterization of Corynespora cassiicola leaf spot fungi from rubber plantations in Sri Lanka. Plant Pathology 47:267-277.

Shimomoto Y, Sato T, Hojo H, Morita Y, Takeuchi S, Mizumoto H, Kiba A, Hikichi Y (2011) Pathogenic and genetic variation among isolates of Corynespora cassiicola in Japan. Plant Pathology 60:253-260.

Sobers EK (1966) A leaf spot disease of azalea and hydrangea caused by Corynespora cassiicola. Phytopathology 56:455-457.

Sokal RR, Rohlf FJ (1995) Biometry: The Principles and Practice of Statistics in Biological Research. 3d. Ed. New York NY, USA. W.H. Freeman and Company.

Souza AF, Costa H, Zambolim L, Mendes C, Freitas RL, Zambolim EM, Jesus Junior WC, Pereira OL (2009) First report of Corynespora cassiicola causing leaf and berry spots on Coffea canephora in Brazil. Australasian Plant Diseases Notes 4:72-74.

Spencer JA, Walters HJ (1969) Variations in certains isolates of Corynespora cassiicola. Phytopathology 59:58-60.

Stone WJ, Jones JP (1960) Corynespora blight of sesame. Phytopathology 50:263-266.

Verzignassi JR, Vida JB, Tessmann DJ (2003) Corynespora cassicola causando epidemias de manchas foliares em pepino 'japonês' sob estufa no norte do Paraná. Fitopatologia Brasileira 28:570.

TPP 2012-0056 - Recebido 6 Julho 2012 - Aceito 26 Fevereiro 2013

Editor de Seção: Nilceu R.X. Nazareno 